\title{
Fusion anomaly of the pancreatic tail and spleen: a case report
}

\author{
Ahmad Khalid Omeri ${ }^{1}$, Shunro Matsumoto ${ }^{1 *}$, Maki Kiyonaga ${ }^{1}$, Ryo Takaji $^{1}$, Yasunari Yamada ${ }^{1}$, Yumiko Ando ${ }^{1}$, \\ Hiromu Mori ${ }^{1}$, Hiroki Uchida ${ }^{2}$, Yukio Iwashita ${ }^{2}$, Masayuki Ohta ${ }^{2}$ and Masafumi Inomata ${ }^{2}$
}

\begin{abstract}
Background: Splenopancreatic fusion is a rare anomaly that is often associated with trisomy 13. Its diagnosis can be important in patients scheduled to undergo distal pancreatectomy or splenectomy, to avoid possible intraoperative or postoperative complications.

Case presentation: An 82-year-old Japanese man was referred to our hospital for further evaluation and treatment for a solitary hepatocellular carcinoma based on liver cirrhosis. Triple-phase contrast-enhanced multidetector-row computed tomography and magnetic resonance imaging showed a splenopancreatic fusion as well as a solitary hepatocellular carcinoma in segment VIII of his liver.
\end{abstract}

Conclusions: Fusion of the pancreatic tail and spleen is a rare and asymptomatic anomaly. Its detection can be improved by the use of multidetector computed tomography or magnetic resonance imaging.

Keywords: Pancreas, Spleen, Multidetector computed tomography, Magnetic resonance imaging, Anomaly, Splenopancreatic fusion

\section{Background}

Splenopancreatic fusion is an uncommon abnormality that is among the splenopancreatic field abnormalities associated with various congenital disorders, mainly trisomy $13[1,2]$. Other splenopancreatic field abnormalities reported in the English language literature include ectopic pancreatic tissue in the spleen or accessory spleen, ectopic splenic tissue in the pancreas, as well fusion of the pancreatic tail and splenic hilum or accessory spleen [1-4]. While their pathological aspects have been described, only one case report has considered their radiological findings [5]. Here we report a case of splenopancreatic fusion in an 82-year-old man and discuss the imaging findings obtained using triple-phase contrast-enhanced multidetector-row computed tomography (3P-CE-MDCT) and contrast-enhanced magnetic resonance imaging (MRI).

\footnotetext{
* Correspondence: matsushu@oita-u.ac.jp

'Department of Radiology, Faculty of Medicine, Oita University, 1-1 Idaigaoka, Hasama-machi, Yufu city 879-5593, Oita, Japan

Full list of author information is available at the end of the article
}

\section{Case presentation}

An 82-year-old Japanese man with a history of liver cirrhosis developed a solitary hepatocellular carcinoma (HCC) in segment VIII of his liver. He was referred to our hospital for further evaluation and treatment although he had no symptoms. He had no medical, family, or psychosocial history related to the disease, nor did he have a history or findings of congenital disorders. A physical examination revealed no significant findings. Laboratory tests showed elevated serum aspartate aminotransferase $(0.83 \mu \mathrm{kat} / \mathrm{L})$, alanine aminotransferase $(0.99 \mu \mathrm{kat} / \mathrm{L})$, and total bilirubin $(20.35 \mu \mathrm{mol} / \mathrm{L})$. Testing for the hepatitis $\mathrm{C}$ virus antibody was positive, and serum tumor markers for HCC were elevated: alphafetoprotein (AFP) $13.5 \mathrm{ng} / \mathrm{mL}$, protein induced by vitamin $\mathrm{K}$ absence/antagonist-II (PIVKA-II) $68 \mathrm{mAU} / \mathrm{mL}$. Other laboratory test results were within normal limits.

Three days after admission, he underwent unenhanced multidetector-row computed tomography (MDCT) and 3P-CE-MDCT examinations. The former revealed a solitary hypodense mass in segment VIII of his liver and continuity of the pancreatic tail with the spleen, which was also noted on 3P-CE-MDCT images (Fig. 1). Curved multiplanar reconstructed images showed that the 

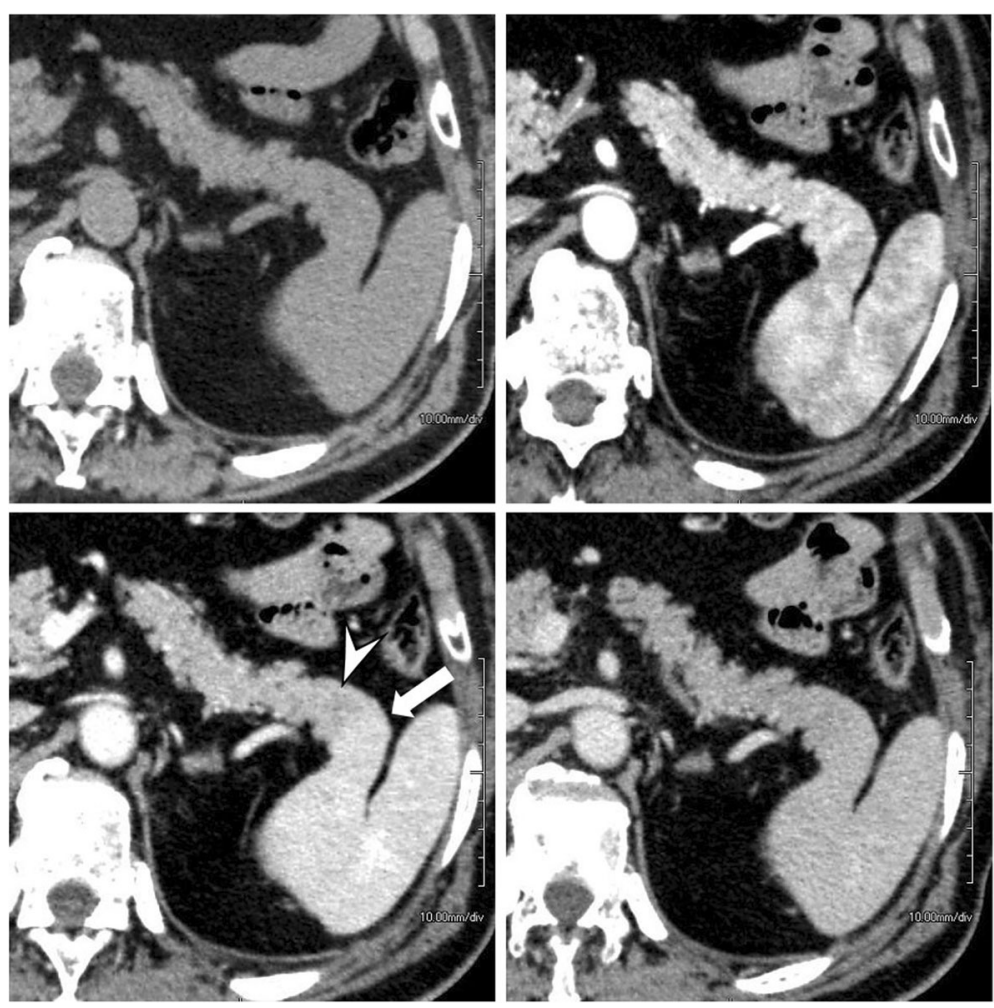

Fig. 1 Axial triple-phase contrast-enhanced multidetector-row computed tomography images show the pancreatic tail in continuity with the spleen. The boundary between the organs is difficult to identify on unenhanced multidetector-row computed tomography (upper left); however, in the portal venous phase (lower left), the boundary between the pancreas (arrowhead) and spleen (arrow) is clearly visible

pancreatic tail was fused to the lower pole of his spleen (Fig. 2). The pancreatic tissue showed homogenous contrast enhancement during the arterial phase, and the splenic tissue the expected heterogeneous pattern. On the portal venous phase, the spleen became homogenous and intensely enhanced compared to the pancreatic tissue, with a distinct line of demarcation between the two organs. Both showed nearly similar contrast enhancement during the delayed phase. Colored maps of the axial and coronal images reformatted from the portal venous phase clearly depicted the fusion border and distinguished between splenic and pancreatic tissues (Fig. 3).

One week after the MDCT examination, he underwent MRI; in-phase and out-of-phase T1-weighted images (T1WI), T2-weighted images (T2WI), and dynamic contrast-enhanced fat suppressed T1WI were obtained. A fat plane between the pancreatic tail and splenic tissue could not be identified on out-of-phase T1WI, again suggestive of fusion. In-phase T1WI clearly distinguished the border between the two tissues based on the differences in signal intensity. However, on T2WI, the fusion border could not be easily identified. Fat-suppressed T1WI after gadoliniumethoxybenzyl-diethylenetriamine pentaacetic acid (Gd-EOBDTPA) administration showed a pattern of contrast enhancement similar to that seen on 3P-CE-MDCT (Fig. 4).
Our patient underwent laparoscopic liver resection for HCC in segment VIII. His postoperative course was uneventful and he was discharged 2 weeks after surgery. However, HCC recurrence was detected on follow-up CT performed 6 months after his discharge from our hospital. He was treated several times with transarterial chemo-embolization for recurrent HCC, but he died 2 years after the initial admission to our hospital, due to the progression of the tumor.

\section{Discussion}

Fusion of the pancreatic tail and spleen reflects their disturbed embryogenesis, as the two organs are located in the dorsal mesoduodenum and dorsal mesogastrium, respectively, and are thus in close proximity $[6,7]$. The pancreas is formed by the union of ventral and dorsal buds originating in two different regions in the distal foregut. The ventral bud, which arises from the hepatic diverticulum, develops into the inferior portion of the pancreatic head and uncinate process. The dorsal bud, which arises from the duodenum, develops into the superior portion of the head, body, and tail of the pancreas. The two primordia fuse after a $180^{\circ}$ rotation of the duodenum at the end of 6th week of gestation. The head and body of the pancreas grow within the dorsal 

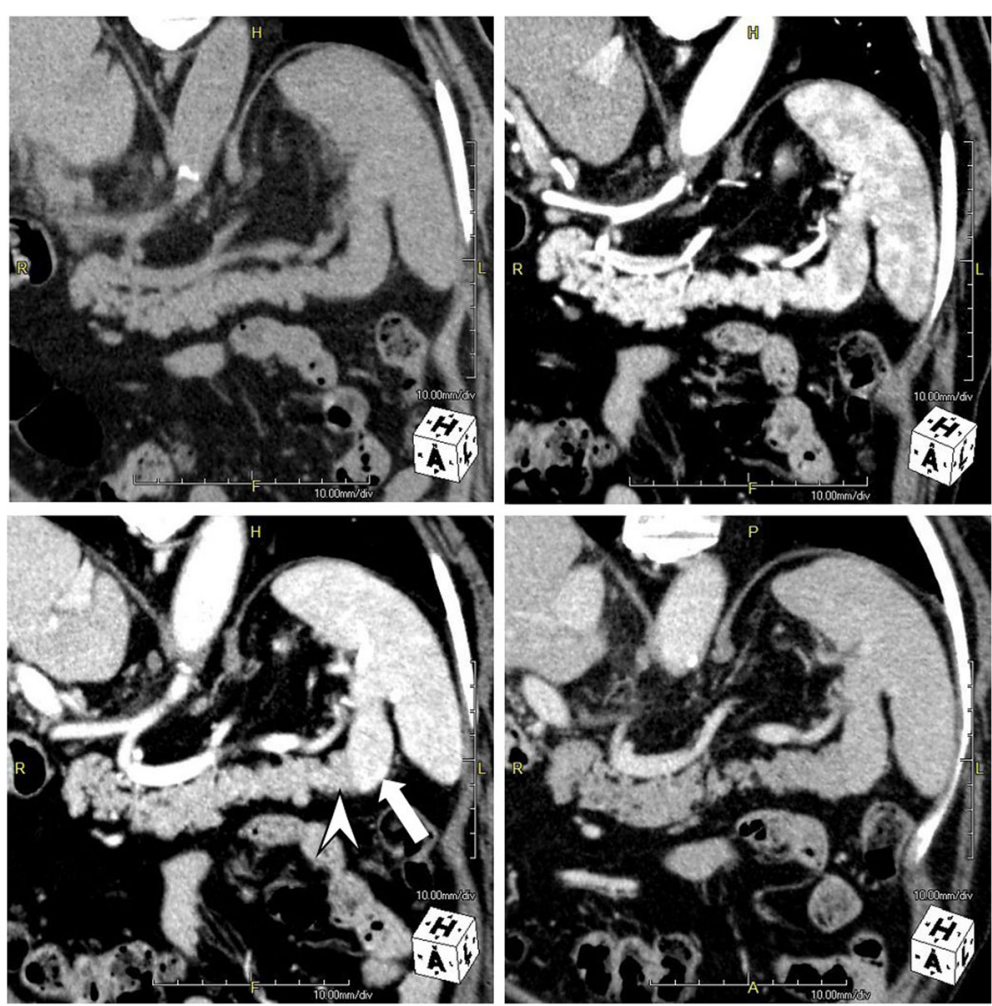

Fig. 2 Coronal multiplanar reconstructed images of triple-phase contrast-enhanced multidetector-row computed tomography show fusion of the pancreatic tail (arrowhead) to the lower medial pole of the spleen (arrow), resulting in its bi-loaded configuration

mesoduodenum and extend to the dorsal mesogastrium, whereas the tail of the pancreas lies within the dorsal mesogastrium [8-10].

The spleen arises as multiple mesenchymal buds that condense between the folds of the dorsal mesogastrium during the 5 th week of gestation $[7,11]$. During the 10th week, because of the counterclockwise rotation of the stomach and duodenum, the mesogastrium and mesoduodenum swing to the left, thus making a hairpin turn at the spleen [10] and positioning the pancreatic tail and spleen in the left upper quadrant. The splenic primordia coalesce to yield a single splenic mass by the end of the 12th week $[7-9,11]$. During these processes, a disturbance in the embryogenesis of one or both organs may result in several anomalous conditions, including one or multiple accessory spleens around the pancreatic tail, intrapancreatic accessory spleen, and, as in our patient, fusion of the pancreatic tail and spleen [5, 9, 11-13]. We speculate that the development of one of the splenic buds in the lower dorsal mesogastrium is partially arrested by the pancreatic tail, located

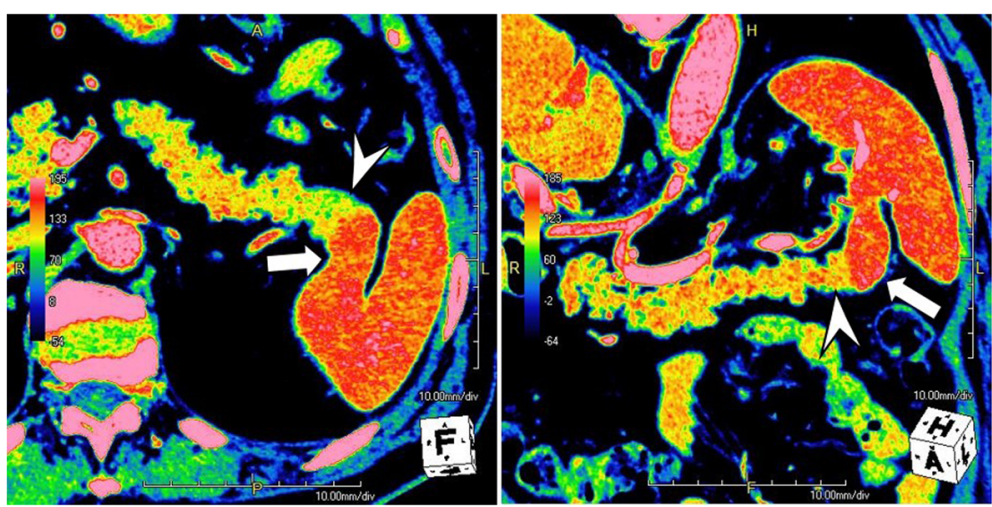

Fig. 3 Colored maps of the axial and coronal multiplanar reconstructed images obtained in the portal venous phase easily differentiated the pancreas (arrowhead) and spleen (arrow) based on differences in their contrast enhancement patterns 

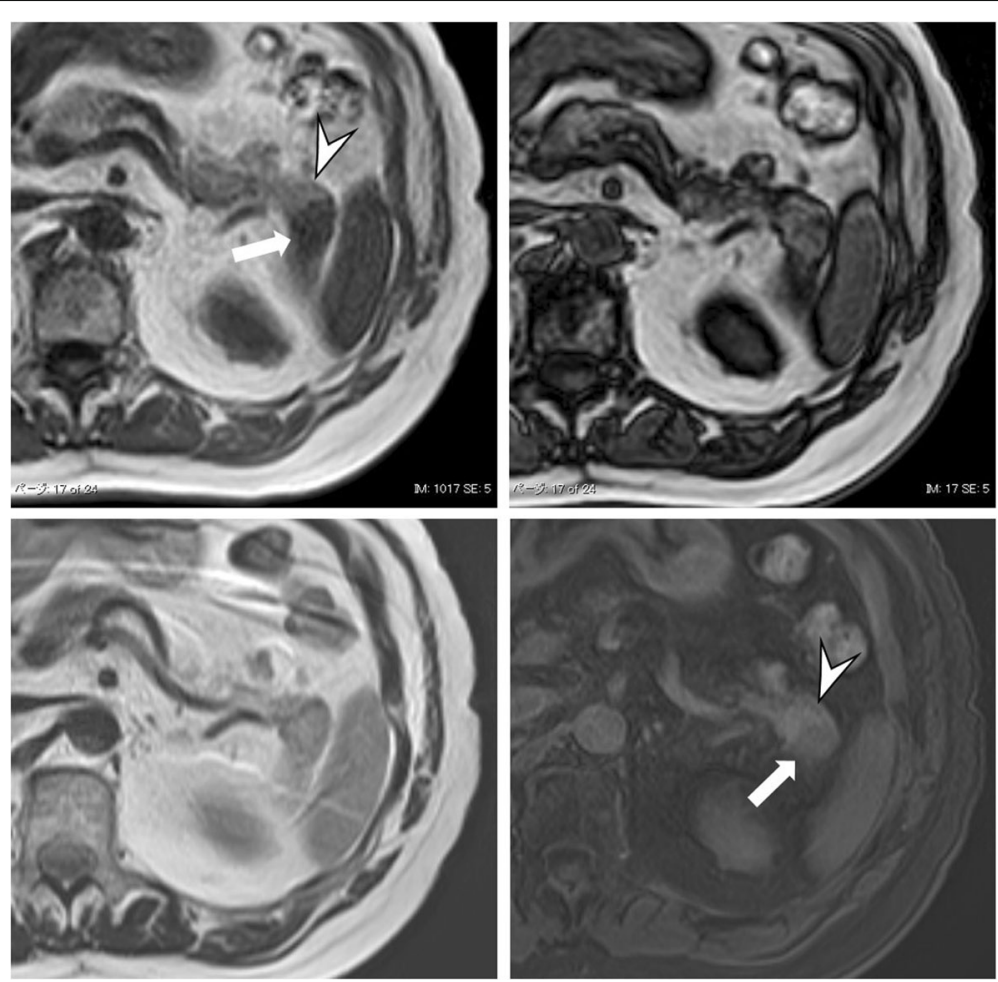

Fig. 4 In-phase T1-weighted image (upper left) clearly shows the boundary between the pancreatic tail (arrowhead) and the spleen (arrow). On out-of-phase T1-weighted image (upper right), a fat plane between the pancreatic tail and splenic tissue could not be identified and thus suggested fusion. T2-weighted image could not identify the fused border. Fat-suppressed T1-weighted image after gadolinium-ethoxybenzyl-diethylenetriamine pentaacetic acid (lower right) differentiated between the two tissues based on their contrast differences

in the same region, such that, later on, the free surface of the splenic bud coalesces with the main splenic mass. This sequence of events is supported by the case reported by Balli et al. [5], in which, as in our patient, the pancreatic tail was fused to the medial aspect of the lower pole of the spleen.

Yang et al. [1] reported two cases of trisomy 13 associated with fusion of the pancreatic tail and spleen and concluded that splenopancreatic fusion suggests a diagnosis of trisomy 13. Gomi et al. [2] reviewed the macroscopic and microscopic findings of 21 individuals with trisomy 13 and compared them with those of 1060 controls without trisomy 13. Fusion of the pancreatic tail and splenic hilum and/or accessory spleen was noted in 17 of the 21 patients, versus only 2 of the 1060 controls. By contrast, Peres et al. [3] reported four cases of splenopancreatic fusion occurring together with other congenital anomalies, including trisomy 21, osteocraniostenosis syndrome, isolated congenital heart defect, and prune belly syndrome, but none of these patients had trisomy 13. The authors therefore concluded that splenopancreatic fusion should not be interpreted as pathognomonic of trisomy 13. Lehman et al. [4] also reported a case of splenopancreatic fusion associated with Schinzel-Giedion syndrome.
Our report includes a description of the 3P-CE-MDCT and MRI contrast enhancement patterns that characterized the splenopancreatic fusion in an otherwise developmentally normal patient. These radiological findings may assist radiologists in establishing the correct diagnosis and may prevent costly and unnecessary examinations. They are also important for surgeons treating patients scheduled to undergo distal pancreatectomy or splenectomy, to avoid possible intraoperative or postoperative complications such as bleeding or pancreatic ductal leaks.

\section{Conclusions}

Splenopancreatic fusion is an uncommon, asymptomatic congenital abnormality, but the use of MDCT or MRI may increase the rate of its detection.

\section{Abbreviations}

3P-CE-MDCT: Triple-phase contrast-enhanced multidetector-row computed tomography; CT: Computed tomography; HCC: Hepatocellular carcinoma; MDCT: Multidetector-row computed tomography; MRI: Magnetic resonance imaging; T1Wl: T1-weighted images; T2Wl: T2-weighted images

\section{Acknowledgements}

Not applicable.

\section{Funding}

The authors declare that this work has not received any funding. 


\section{Availability of data and materials}

All data generated or analyzed during this study are included in this published article.

\section{Authors' contributions}

AKO and SM wrote and edited the manuscript. MK, RT, YY, and YA interpreted the 3P-CE MDCT and MR images. $\mathrm{HU}$ and $\mathrm{Yl}$ obtained the patient's history and performed the physical examination. $\mathrm{HM}, \mathrm{MO}$, and $\mathrm{MI}$ reviewed the manuscript. All authors read and approved the submitted version of the manuscript.

\section{Ethics approval and consent to participate}

This study was approved by the Ethical Review Board of Oita University Faculty of Medicine, Japan.

\section{Consent for publication}

Written informed consent was obtained from the patient's next-of-kin for publication of this case report and any accompanying images. A copy of the written consent is available for review by the Editor-in-Chief of this journal.

\section{Competing interests}

The authors declare that they have no competing interests.

\section{Publisher's Note}

Springer Nature remains neutral with regard to jurisdictional claims in published maps and institutional affiliations.

\section{Author details}

'Department of Radiology, Faculty of Medicine, Oita University, 1-1 Idaigaoka, Hasama-machi, Yufu city 879-5593, Oita, Japan. ${ }^{2}$ Department of Gastroenterological and Pediatric Surgery, Faculty of Medicine, Oita University, Yufu, Oita 879-5593, Japan.

Received: 29 January 2017 Accepted: 19 July 2017

Published online: 27 August 2017

\section{References}

1. Yang XY, Heller DS, Baergen RN. Splenopancreatic field abnormality in trisomy 13. Pediatr Dev Pathol. 2002;5(4):414-5. doi:10.1007/s10024001-0257-1.

2. Gomi K, Sato Y, Tanaka M, ljiri R, Kato K, Aoki I, Tanaka Y. Specificity of splenopancreatic field abnormality in trisomy 13 syndrome: macroscopic and histological analysis in 21 autopsy cases. Pathol Int. 2009;59(3):147-51. doi:10.1111/j.1440-1827.2009.02342.x.

3. Peres $L C$, Barbosa GH, Careta RS, Nassif $C M$, de Pina-Neto JM, Giuliani $L R$, Martinhago CD, Gomy I. Splenopancreatic field abnormality is not unique to trisomy 13. Pediatr Dev Pathol. 2004;7(1):91-4. doi:10.1007/s10024-003-6067-x.

4. Lehman AM, McFadden D, Pugash D, Sangha K, Gibson WT, Patel MS. Schinzel-Giedion syndrome: report of splenopancreatic fusion and proposed diagnostic criteria. Am J Med Genet A. 2008;146A(10):1299306. doi:10.1002/ajmg.a.32277.

5. Balli O, Karcaaltincaba M, Karaosmanoglu D, Akata D. Multidetector computed tomography diagnosis of fusion of pancreas and spleen confirmed by magnetic resonance imaging. J Comput Assist Tomogr. 2009; 33(2):291-2. doi:10.1097/RCT.0b013e31817d74f7.

6. Brookes M, Zietman AL. Chapter 42: Duodenum and pancreas. In: Brookes M, Zietman AL, editors. Clinical Embryology. A Color Atlas and Text. Florida: CRC Press; 1998. p. 172-5.

7. Moore KL, Persaud TNV. Chapter 12: The Digestive System. In: Moore KL, Persaud TNV, editors. The Developing Human: Clinically Oriented Embryology. 6th ed. Philadelphia: W. B. Saunders Company; 1998. p. 271-302

8. Fitzgerald MJT, Fitzgerald M. Chapter 19: Abdomen: the foregut and its mesenteries. In: Fitzgerald MJT, Fitzgerald M, editors. Human Embryology. London: Bailliere Tindall; 1994. p. 119-27.

9. Javors BR, Mori H, Meyers MA, Wachberg RH. Chapter 2: Clinical Embryology of the Abdomen: Normal and Pathologic Anatomy. In: Meyers MA, editor. Dynamic Radiology of the Abdomen: Normal and Pathologic Anatomy. 5th ed. New York: Springer; 2000. p. 32-44.

10. Dodds WJ, Darweesh RM, Lawson TL, Stewart ET, Foley WD, Kishk SM, Hollwarth M. The retroperitoneal spaces revisited. AJR Am J Roentgenol. 1986;147(6):1155-61. doi:10.2214/ajr.147.6.1155.
11. Brookes M, Zietman AL. Chapter 39: Stomach and spleen. In: Brookes M, Zietman AL, editors. Clinical Embryology. A Colour Atlas and Text. Florida: CRC Press; 1998. p. 160-3.

12. Kim SH, Lee JM, Han JK, Lee JY, Kim KW, Cho KC, Choi BI. Intrapancreatic accessory spleen: findings on MR Imaging, $C T$, US and scintigraphy, and the pathologic analysis. Korean J Radiol. 2008;9(2):162-74. doi:10.3348/kj.2008.9.2.162.

13. Spencer LA, Spizarny DL, Williams TR. Imaging features of intrapancreatic accessory spleen. Br J Radiol. 2010;83(992):668-73. doi:10.1259/bjr/20308976.

\section{Submit your next manuscript to BioMed Central and we will help you at every step:}

- We accept pre-submission inquiries

- Our selector tool helps you to find the most relevant journal

- We provide round the clock customer support

- Convenient online submission

- Thorough peer review

- Inclusion in PubMed and all major indexing services

- Maximum visibility for your research

Submit your manuscript at www.biomedcentral.com/submit
Biomed Central 